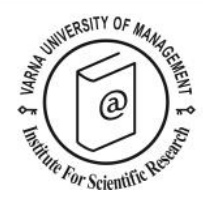

\title{
The role of social organisations in the promotion of recreation and tourism activities for people with special needs
}

\author{
Maria João Carneiro ${ }^{{ }^{*}}$, Joana Pimentel Alves ${ }^{2}$, Celeste Eusébio ${ }^{3}$, Liliana Saraiva ${ }^{4}$ and \\ Leonor Teixeira 5
}

1 Governance, Competitiveness and Public Policy (GOVCOPP) research unit, Department of Economics, Management, Industrial Engineering and Tourism, University of Aveiro, Aveiro, Portugal, E-mail: mjcarneiro@ua.pt

${ }^{2}$ Department of Economics, Management, Industrial Engineering and Tourism, University of Aveiro, Aveiro, Portugal, E-mail: joanapimentelalves@ua.pt

3 Governance, Competitiveness and Public Policy (GOVCOPP) research unit, Department of Economics, Management, Industrial Engineering and Tourism, University of Aveiro, Aveiro, Portugal, E-mail: celeste.eusebio@ua.pt

4 Department of Economics, Management, Industrial Engineering and Tourism, University of Aveiro, Aveiro, Portugal, E-mail: lcsaraiva@ua.pt

5 Institute of Electronics and Informatics Engineering of Aveiro (IEETA), Department of Economics, Management, Industrial Engineering and Tourism, University of Aveiro, Aveiro, Portugal, E-mail: lteixeira@ua.pt

${ }^{*}$ Corresponding author

\begin{abstract}
Although leisure and tourism are recognised as rights for all people, many people with special needs (PwSN) still have very limited opportunities for participating in these activities. Social organisations (SO) are potential mediators between the tourism industry and this market, especially for reducing barriers to participation. However, there is a lack of research on the role these organisations perform as facilitators of access to leisure and tourism. This paper aims to identify the difficulties faced and strategies adopted by SO when developing recreation and tourism activities, as well as the benefits of these activities for PwSN. A qualitative approach was adopted, namely semi-structured interviews with representatives of Portuguese SO working with PwSN. The findings highlight that Portuguese SO have had a dynamic and proactive behaviour in the development of recreation and tourism activities, contributing to increased access of PwSN to tourism activities, especially for people belonging to socially and economically disadvantaged groups. However, the results also show that SO face several constraints, specifically financial constraints, lack of specialised human resources and the lack of suitable tourism supply (e.g. accommodation, transportation) for this market. The paper ends with strategies that these organisations may adopt to cope with these constraints.
\end{abstract}

Key words: disability studies; accessible tourism; social organisations; people with special needs; people with disabilities; qualitative study

Citation: Carneiro, M.J., Alves, J.P., Eusébio, C., Saraiva, L. and Teixeira, L. (2022). The role of social organisations in the promotion of recreation and tourism activities for people with special needs. European Journal of Tourism Research 30, 3013.

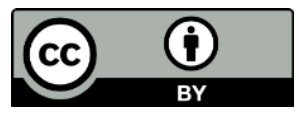




\section{Introduction}

In December 2006, in the resolution 61/106 of 13 December, the United Nations General Assembly proclaimed the Convention on the Rights of Persons with Disabilities (PwD). The article 30 recognised the participation in leisure activities as a right and underlined that people with disabilities (PwD) should participate in those activities under the same conditions as people without disabilities. It also stated that disability should not be a hindrance to a full participation in recreation and cultural life or even in sports for people with these circumstances (UN-United Nations, 2007). However, studies about people with special needs (PwSN), who include PwD (e.g. mobility, vision, hearing, intellectual/cognitive, mental health), seniors and people with other specific needs related to health or personal physical conditions (e.g. respiratory, food allergies), reveal that these people have low levels of participation in society comparing with other citizens (Eusébio et al., 2016; Melbøe \& Ytterhus, 2017; Solish et al., 2003). This low participation has multiple causes. The characteristics of the physical environment and of transportation, difficulties in communication, lack of access to information, inappropriate attitudes of the community and financial factors, are commonly identified by PwSN and their families as constraints to participating in different kinds of activities (Freund et al., 2019; Gillovic, 2019; Innes et al., 2016; Reynolds, 2002; Russell, 2009).

Nowadays, several constraints continue to be identified as causes for low levels of participation of PwSN in the community, including recreation and tourism activities, especially affecting people with highlevel dependency (e.g. people with intellectual disabilities and high support needs) (Melbøe \& Ytterhus, 2017; Venema et al., 2018; Verdonschot et al., 2009a). Situations of dependence tend to increase with the aging of the population (Melbøe \& Ytterhus, 2017; Solish et al., 2003). The low levels of participation in all domains of the public sphere, as a result of these multiple barriers, are against international recommendations (UN-United Nations, 2007). Moreover, some studies highlight that the participation in leisure and tourism improves the well-being or quality of life of PwSN and their families (Innes et al., 2016; Morgan et al., 2015; Richards et al., 2010; Yau et al., 2004).

Previous studies also emphasise that the existence of multiple barriers makes the presence of caregivers indispensable in PwSN's lives, to ensure their full participation in daily activities (Bedini \& Phoenix, 1999; Gillovic, 2019; Triantafillou et al., 2011), including their participation in recreation and tourism activities. Many caregivers work in social organisations (SO) (e.g. non-governmental organisations, associations, charities, foundations and cooperatives) giving everyday assistance in various aspects of PwSN's daily lives, including support for participation in recreation and tourism activities. Despite the importance of these organisations, most of the research on tourism and PwSN focus on the demand, examining the needs, travel behaviour and outcomes of tourism of this group of people, among other aspects (Bergier et al., 2011; Blichfeldt \& Nicolaisen, 2011; Figueiredo et al., 2012; Lee et al., 2012; Lovelock, 2010). The literature on the supply mainly focus on how some kind of suppliers, such as hotels and resorts (Lee et al., 2012; Tutuncu \& Lieberman, 2016) and tourism attractions like museums (Mesquita \& Carneiro, 2016; Papadimitriou et al., 2016), adapt or should adapt to cater these people's needs. However, there is a lack of research on the role of SO in boosting accessible tourism, especially empirical studies, regarding the functions they perform in the scope of tourism, their difficulties in this field, and also on the benefits they generate to PwSN. Although some literature suggests that SO may play a relevant role in this scope, literature is very scarce in this field and simply suggests some activities that these organisations may perform (Hunter-Jones, 2011), instead of giving an overall perspective on the role of these organisations. Blichfeldt and Nicolaisen (2011) have highlighted the contrast between the crucial role played by $\mathrm{SO}$ in the field of disability in the promotion of recreation and tourism activities and the lack of studies about this topic. This lack of information is especially surprising since PwSN receive great support from SO (like day centres) (Melbøe \& Ytterhus, 2017). Scarce literature and the 
importance of SO in promoting the participation of $\mathrm{PwSN}$ in recreation and tourism activities make this field a research priority in accessible tourism studies.

To overcome the research gap identified, this paper intends to analyse the role of a group of Portuguese social organisations (SO) in promoting the participation of PwSN in recreation and tourism activities through a qualitative approach. Specifically, the paper aims to answer the following questions: 1) What type of recreation and tourism activities are offered by SO? 2) Why do SO provide recreation and tourism activities? 3) Which constraints do SO face in organising recreation and tourism activities? 4) Which strategies do SO use to plan recreation and tourism activities? and 5) Which strategies can be used to improve the role of SO in the development of accessible tourism?

This paper provides relevant theoretical contributions, increasing knowledge on the role of SO in the development of tourism activities. Moreover, important practical contributions are also offered to help SO design strategies to diversify their services to improve the well-being of PwSN.

To accomplish the previously identified objectives, this paper is organised into five sections. After this introduction, a literature review on the role of SO in the promotion of recreation and tourism activities will be presented, specifically analysing the type of recreation and tourism activities promoted by these organisations, the benefits obtained with these activities and the difficulties that these organisations face in planning and offering this kind of activities to PwSN. The third section includes the methodology used to collect and analyse the data in the empirical study. The results obtained will then be described and discussed. Finally, the paper ends with the most important conclusions, theoretical and practical contributions, limitations and suggestions for further research.

\section{Literature Review}

The relevance of recreation and tourism activities for PwSN

Since the 1940s, leisure and holidays are human rights, declared by United Nations (1948). However, many people have these rights denied or hindered due to several constraints (Eusébio et al., 2016). In this context, accessible tourism intends to overcome this exclusion, enabling all people, including those with functional and other kinds of special needs, to access tourism products independently, with equity and dignity (Darcy \& Dickson, 2009). Although there are efforts to make tourism inclusive for all, the discussions about participation of PwSN in recreation and tourism activities have clearly evidenced that structural and individual factors have an impact both on individuals' choices and on their possibilities to participate in these activities (Badia et al., 2013; Beart et al., 2001; Henderson et al., 1995). Although accessible tourism has registered a great progress worldwide in the last 20 years (Darcy et al., 2020), supply agents must still undertake several efforts to mitigate travel constraints that PwSN face in carrying out recreation and tourism activities.

Since 1980s, barriers and constraints to leisure and travel have been object of research (Bauer, 2018). In late eighties, Crawford and Godbey (1987) developed a model that categorised the constraints on participating in leisure activities into three types: intrapersonal (individual factors, which affect their leisure preferences), interpersonal (social factors that also affect the individual's leisure preferences) and structural (environmental factors that inhibit the participation of individuals). Some years later, Crawford et al. (1991) extended this model and presented a hierarchical model of leisure constraints, "which posited that intrapersonal and interpersonal constraints affect leisure preferences whereas structural constraints intervene between preferences and participation" (White, 2008: 344). After more than thirty years, this contribution is still considered of enormous importance in the field of leisure and tourism constraints (Nyaupane \& Andereck, 2008). 
Another relevant contribution to the literature on tourism constraints is the work of Smith (1987). In this work, he identified and categorised barriers to participation in leisure activities faced by PwD. According to the author, all tourists face barriers to their participation in these activities, which have an impact on their feelings of autonomy. However, while it is true that barriers can be a reality for anyone, it is also true that barriers can have specific implications in the case of PwD, with a huge impact on their satisfaction. According to Smith (1987), there are three types of barriers: intrinsic (e.g. problems related to health, lack of knowledge, physical and psychological dependence); environmental (e.g. attitudinal, architectural, and ecological); and interactive (e.g. problems with communication skills). This was one of the earliest studies to describe barriers faced by PwD (Evcil, 2018) and one of the most relevant works in this area until today, since it focus its analysis in non-participation and in lack of leisure opportunities.

More recent studies about accessible tourism still evidence enormous constraints and difficulties faced by PwSN and their families when aiming to participate in recreation and tourism activities (Daniels et al., 2005; Devile \& Kastenholz, 2018; Gassiot et al., 2018; Griffin \& Stacey, 2011; Innes et al., 2016; Patterson et al., 2012). However, the group of PwSN is heterogeneous in terms of characteristics, needs and constraints on participating in recreation and tourism activities. These needs and constraints are the result not only of the biological characteristics of the individuals, but also the characteristics of the physical and social environment (Eisenberg \& Maisel, 2021; Froehlich-Grobe et al., 2021; Thomas, 2007). These special needs could be of a permanent or a temporary nature (McCabe \& Diekmann, 2015). Therefore, this is a heterogeneous market (Figueiredo et al., 2012). Considering the three main groups under analysis here, PwD could have restrictions in mobility, vision, hearing and cognitive, which result in different types of constraints and needs. For people with physical disabilities, structural constraints, such as inaccessibility to a physical environment, are the most inhibiting barriers (Card et al., 2006; Daniels et al., 2005; Ray \& Ryder, 2003). On the other hand, for people with sensory disabilities (e.g. blind, low sighted people and deaf) the main barriers are the access to information and communication (e.g. inability to access visual or audio information, difficulties in mobility in unfamiliar environments) (Constantinou et al., 2016; Devile \& Kastenholz, 2018; Hersh, 2016; Small, 2015; Zajadacz, 2014). People with intellectual disabilities have difficulties in problem-solving and adaptive behaviour, which require adaptations in information and communication (e.g. use of simple language, pictograms) and assistance of another person (e.g. in transports use, to interpret schedules, in personal care) (Beart et al., 2001; Gillovic, 2019; Innes et al., 2016). The special needs of seniors result from the ageing process and can affect their mobility, senses (e.g. deafness), or even cause restrictions in mental functions (e.g. severe depressions, or dementia). Finally, in the case of people with other special needs (e.g. people with food and respiratory allergies), constraints directly result from their type of special needs and from the lack of appropriate tourism supply. For example, people with food allergies and intolerances have difficulty in finding adequate meals and in avoiding allergens when travelling (Barnett et al., 2012; Comstock et al., 2008). This condition prevents people with food alergies from travelling regularly, forcing them to adopt some preventive behaviours (e.g. avoid consuming local products, asking about food composition and travelling with their own food) (Kanny, 2015).

However, despite all the constraints and difficulties, many PwSN want to engage in recreation and tourism activities (Allan, 2015; Figueiredo et al., 2012; Kastenholz et al., 2015; Ray \& Ryder, 2003; Smith, 1987; Yau et al., 2004). Families with PwSN also attest this will (Kim \& Lehto, 2012). Recreation and tourism activities are tools for social inclusion of PwSN and have a positive impact on their lives (Figueiredo et al., 2012; Kastenholz et al., 2015; Moura et al., 2018; Pagán, 2015) and their families' lives (Kim \& Lehto, 2012; Lehto et al., 2018; Sedgley et al., 2017). The benefits obtained through participation have an important impact on mental health (increasing well-being, reducing the levels of loneliness) 
and physical health (improvement of physical skills and competences), but also on the social life of PwSN (contributing to personal development, social inclusion and participation) (Kastenholz et al., 2015; Moura et al., 2018). Moreover, participation in recreation and tourism activities can improve the quality of life of PwSN by enhancing physiological, psychological and social well-being and increasing peoples' autonomy, self-esteem, confidence, humour, mood and social participation (Morgan et al., 2015; Shaw \& Coles, 2004).

Previous studies have also revealed that the benefits obtained from recreation and tourism activities may somewhat differ according to the type of special need. For PwD, engaging in this type of activities is seen as an opportunity to increase their levels of well-being and self-confidence, to escape from their usual routine, to get away from their usual care environment, and to feel free (Bauer, 2018; Blichfeldt \& Nicolaisen, 2011; Eichhorn et al., 2013; Figueiredo et al., 2012; Hersh, 2016). For families with dependent persons (e.g. children, PwD, seniors with dementia) participation in these activities is an opportunity to relax and escape from routine, to socialize with other people, but also to spend quality time with family and in activities to improve the development of physical and intellectual competences of their family member with special needs (Innes et al., 2016; Kim \& Lehto, 2013). Recreation and tourism activities also have great benefits for seniors, specifically in improving their health and preventing social isolation (Patterson \& Balderas, 2020; Zhang \& Zhang, 2018).

Despite the important benefits of recreation and tourism activities to PwSN, the whole travel process of these people that require significant planning time and careful attention (Daniels et al., 2005) by PwSN (Devile \& Kastenholz, 2018), their families (Nyman et al., 2018) or by SO (formal caregivers) that give support to PwSN.

The role of social organisations in the promotion of recreation and tourism activities

The literature emphasises that when PwSN want to engage in recreation and tourism activities, the multiple barriers they face make the presence of formal or informal caregivers essential to ensure their full participation (Bedini \& Phoenix, 1999; Triantafillou et al., 2011). Informal caregivers are unpaid providers, usually family members, relatives or neighbours, with no training to ensure their care responsibilities (European Commission, 2007; Goodhead \& Mcdonald, 2007; Portugal \& Alves, 2015). The type of tasks they perform are multiple and vary with the need of PwSN they support. Thereby, they can give support in daily routine activities, instrumental activities, companionship and emotional support, among other domains (Alves, 2016; Goodhead \& Mcdonald, 2007; Triantafillou et al., 2011).

Formal caregivers are paid professionals who provide care services for people and usually work in governmental or private enterprises, or in SO. They perform care services that need licensed training (these services are usually performed by professionals such as social workers, nurses, doctors, occupational therapists, physiotherapists), and other tasks which are important to the well-being of PwSN but in which no licensed training is needed (like support in daily activities) (Alves, 2016; Goodhead \& Mcdonald, 2007; Portugal \& Alves, 2015). Some of these caregivers support not only PwSN's daily activities, but also, they facilitate contact with society through the promotion of activities outside institutions. They define, organise, and provide all kinds of information concerning activities that promote contact of PwSN with the outside world, including tourism activities (Blichfeldt \& Nicolaisen, 2011).

SO are a set of civil society organizations with the objective of benefiting the community or its members, with no profit-making purposes (Ferreira, 2009). Their designation varies from country to country, reflecting the history and socio-political situation of each country (Ferreira, 2009; Nogueira, 2017; Vieira, 
2015). For example, in North America, the common term is non-profit sector or non-profit organisations (Salamon et al., 2000; Salamon \& Anheier, 1992), in France the term "social economy" is used, in AngloSaxon countries the terms "voluntary sector", "third sector" and "non-governmental organisations (NGOs)" are frequently employed (Salamon \& Anheier, 1992) and in the United Kingdom, the expression "charities" is often adopted (Adalbert \& Laville, 2004). In Portugal, these organisations are part of third sector organizations (TSO), and can take different typologies, such as NGOs, private institutions of social solidarity (IPSS), associations, charities (Misericórdias), foundations and cooperatives (INE, 2019; Vieira, 2015). Moreover, in Portugal this type of organisation operates in different areas (e.g. social, cultural, recreational, sports and local development areas). Therefore, SO are a habitual presence in the everyday lives of PwSN, especially in cases of high-level dependency. In activities outside the home or institutions such as recreation and tourism activities, their presence and support is just an extension of their role. Therefore, caregivers can give continuous support to many PwSN before, during and after a recreation or tourism activity.

Despite SO traditionally having the role of service providers to their members (Neumayr \& Meyer, 2010; Salamon et al., 2000; Salamon \& Anheier, 1992), nowadays these organisations have a multi-sectorial nature that enables them not only to provide daily life-support services, but to explore other areas of activity, such as culture, environment, or even tourism (Noya \& Clarence, 2008). However, a limited number of authors have examined the role of $\mathrm{SO}$ in the offer of recreation and tourism activities to PwSN (Hunter-Jones, 2011; Loi \& Kong, 2015; Turner et al., 2001). These organisations can play a crucial role in promoting recreation and tourism activities for their members (Loi \& Kong, 2015), since they know their characteristics, needs and constraints. Therefore, they are able to identify the constraints that inhibit effective participation, select suitable products and experiences according to their members' profile, and may also obtain funds to finance recreation and tourism activities (Loi \& Kong, 2015). Moreover, these organisations can also stimulate the desire of PwSN to participate in activities that enable them to develop their skills, which is especially relevant to members who have no opportunity to participate in these activities outside the SO, mainly due to lack of financial resources, lack of companionship or inability to plan and organize tourism trips.

As far as tourism is concerned, literature only provides very general insights concerning the support that SO can provide to PwSN, such as financial support, provision of tourism facilities, or organization of tourism activities, such as tourism trips (Diekmann \& McCabe, 2011; Hunter-Jones, 2011). Regarding recreational and tourism activities, the main activities identified in the literature that are offered by SO are recreation activities, especially participation in sports, arts, socialising, and cultural events (Abraham et al., 2002; Hall \& Hewson, 2006; Verdonschot et al., 2009a). However, in some cases, activities are determined by therapeutic and rehabilitation proposals (Ager et al., 2001). The presence of SO staff during the activities promoted in community settings is common (Ager et al., 2001; Ashman \& Suttie, 2007). The support of SO during the activities is a crucial factor for the participation of PwSN, especially in cases of high-level dependency (physical or intellectual) (Ager et al., 2001; Verdonschot et al., 2009b).

Despite the relevance of recreation and tourism activities offered by SO to enhance the well-being and social inclusion of their members, these organisations can face various internal and external constraints. However, the literature in this field is very scarce, and no studies are known that examine how these organisations plan recreation and tourism trips and the real internal and external constraints they face. Therefore, it is of utmost relevance to undertake research to listen to these organisations about these issues. 


\section{Methodology}

Context of study

The focus of the empirical study carried out in the present paper is Portuguese SO that promote recreation and tourism activities for PwSN - i.e. seniors, PwD, and people with other needs related to health and physical conditions, like food allergies. In Portugal the majority of SO were created after 1974 (Capucha et al., 1995), and after Portugal joined to European Economic Community (1986) the number of SO increased significantly (Franco et al., 2005). Nowadays, this kind of organisations still have an important role in Portuguese society. The majority of Portuguese organisations result from the initiative of the population to respond collectively to different needs of their peers through the offer of social services, services to respond to emergencies, or for recreational purposes (Franco et al., 2005). These organisations also have a special role in the support and representation of groups of citizens that, for some reason, live in a situation of social exclusion or have a special need. They have multiple areas of intervention such as the support of seniors, PwD and other groups, and aim to overcome the low rate of response from the state to some needs of society. In the present paper, the perspectives of three types of organisations are analysed - SO that support seniors, PwD and people with other special needs (e.g. food allergies).

\section{Social organisations that support seniors}

In 2018, the Portuguese population with 65 years old or over is estimated to be around 2.2 million (INE, 2020). In Portugal there are four types of social facilities specialised in caring for the elderly - day centres, night centres, residential care facilities and Universities of the Third Age (MTSS, 2017). These Universities of the Third Age aim to create, and regularly promote, social, cultural, and educational activities for those over 50 years old, promoting an active aging and encouraging the participation of their associates in the society (RUTIS, n.d.).

\section{Social organisations that support people with disabilities}

In last national census, $18 \%$ of the Portuguese population aged five or over declared that they have great difficulty in accomplishing at least one of the following activities: walking, seeing, memorising, hearing, bathing/dressing and understanding. From the total of the difficulties, 25\% are related to walking, 23\% to seeing, $17 \%$ to memorising, $13 \%$ to hearing, $12 \%$ to bathing and dressing, and $10 \%$ to understanding (INE, 2012). According to Portuguese legislation (Decree-law no 106/2013), non-governmental organisations that provide support to PwD are non-profit organisations. They should pursuit social interests, defending the rights and legally protecting interests of $\mathrm{PwD}$, and promoting the social participation of their members. These organisations represent people with different kinds of disabilities (e.g. mobility, vision, hearing, intellectual/cognitive) as well as their families.

\section{Social organisations that support people with other special needs}

The factors that determine special needs related to health or physical conditions in recreation and tourism go beyond age (in the case of seniors) or disabilities. Other situations, like respiratory disorders, food allergies or intolerances may result in special access requirements to products, services and environments. Although there is no information on the number of SO that represent these groups in Portugal, due to the important role of organisations representing coeliacs, diabetics and other special needs groups (e.g. respiratory diseases), they are also considered in the empirical study carried out in this paper. 


\section{Data collection methods}

As the literature review showed, the studies about the topic under analysis are still limited and the available information does not fully reflect the role of $\mathrm{SO}$ as promoters of recreation and tourism experiences for PwSN. In order to address this gap, a qualitative research was undertaken.

The data were collected through semi-structured interviews, conducted in Portuguese, with representatives of Portuguese SO who work with PwSN (i.e. seniors, PwD, and people with other needs, like food allergies) about their role as promoters of recreation and tourism activities for these groups. The interview script was created based on the literature (Morgan et al., 2015; Yau et al., 2004) and on Portuguese national legislation (e.g. Decree-law no 163/2016). The questions were mainly designed to obtain information from the representatives of the SO about the following: (i) type of recreation and tourism activities that they organise; (ii) why they organise these activities; (iii) difficulties in organising recreation and tourism activities for $\mathrm{PwSN}$ and the planning process implemented to organise these activities; (iv) strategies that have been implemented to improve the role of SO in the organisation of recreation and tourism activities; and (v) characteristics of the SO (e.g. target markets, number of associates).

It is not possible to determine the exact number of PwSN in Portugal nor the number of SO that support this population. Considering that, in order to identify interviewees, a nonprobability sampling method was used, and $\mathrm{SO}$ who corresponded to the profile and were available to participate in the research were selected through a convenience sampling approach. In addition, a snowballing sample method was also applied, in which the interviewees helped to identify other SO.

First, a database of SO supporting PwSN in Portugal was created through a web search on Google, between January and March 2019. SO were selected based on the following keywords: "social organisation”, "formal caregivers" “disability", “impairment,”, “seniors”, “deaf”, "blind”, “intellectual disability", "mental disorders", "respiratory diseases", "food allergy", "food intolerance" and "diabetes". It is important to recognize that this selection method has some limitations, such as the exclusion of $\mathrm{SO}$ with no online presence. However, this was the most appropriate procedure found due to the lack of a database with this information. A total of $130 \mathrm{SO}$ were identified.

All 130 social organisations were invited to participate in the study. Representatives of thirty SO accepted the invitation and were interviewed between February and May 2019. In the majority of the cases, interviews were conducted face to face ( 27 interviews). However, when the interviewees were not available to participate in a face-to-face interview, interviews were carried out online via Skype (three interviews).

Data collection was finished at the point of saturation, a criterion suggested by some researchers (Denscombe, 2007; Whitehead \& Whitehead, 2016). The saturation point varies from research to research (Vasileiou et al., 2018). In this research, the saturation point was reached at the 27th interview when no new data or new themes emerged from the discourses of interviewees. After this point, more three interviews were conducted to confirm that no new data or new themes would emerge.

\section{Data analysis}

The interviews were tape-recorded with the interviewees' permission, transcribed and anonymised. A content analysis was used to analyse the data obtained following the procedures used in Denscombe's work (2007). First, the transcriptions were read in full, searching for the main ideas and issues that emerged from the discourses. In this first step, the main characteristics of the phenomena become 
evident and the data were organised into categories and sub-categories based on the discourses. Second, the categories and sub-categories identified were codified. Third, all created categories, sub-categories and codes were analysed in detail. In this stage of the analysis, the overlapping categories, subcategories, and codes were redefined and only the information regarding the SO's role in the promotion of recreation and tourism experiences was considered.

Although the study is inherently qualitative, quantitative analyses were also conducted to complement the qualitative analysis and to provide a better systematisation of the results obtained. As a result, a part of the analysis was the search for patterns across the 30 interviewees and, to examine the prevalence of certain categories, frequency analysis was also carried out. Hence, the following sections present and discuss both qualitative and quantitative results.

\section{Results and discussion}

Sample profile

Table 1 summarises the profile of the SO interviewed. The sample was somewhat unbalanced considering the target of the SO, with the majority of the organisations that participated in the study supporting $\mathrm{PwD}$ (73.33\%). The sample groups are composed by SO working with people with cognitive or intellectual disabilities (30.00\%), seniors (16.66\%), people with physical disabilities (13.33\%), people with blindness or low vision (10.00\%), the deaf population (10.00\%), all types of disability (10.00\%), and other special needs (e.g. food allergies) (10.00\%).

Almost two thirds of the SO interviewed are located in the Central Region of Portugal (63.33\%), followed by those of the Lisbon Region (16.67\%), North Region (16.67\%) and Alentejo Region (3.33\%). The SO with the highest number of members (26470) is located in the Lisbon Region, supports all types of disabilities, and has been operating for almost 50 years (since 1972). On the other hand, the SO with the lowest number of members (29) is located in the Central Region of Portugal, only works with people with physical disabilities and was founded 19 years ago (2001). There is great variety regarding the number of associates, with $23.33 \%$ of SO having 100 or less associates and $26.67 \%$ having more than 400 . Almost half of the sample were founded in the 2000 s (46.67\%).

Table 1. Profile of social organisations

\begin{tabular}{|c|c|c|c|c|}
\hline SO code & Type of PwSN & NUTS II & $\begin{array}{l}\text { № of } \\
\text { associates }\end{array}$ & $\begin{array}{l}\text { Decade of } \\
\text { foundation }\end{array}$ \\
\hline SO1_Disabilities & $\begin{array}{l}\text { People with cognitive and } \\
\text { intellectual disabilities }\end{array}$ & Central Region & * & $2000 \mathrm{~s}$ \\
\hline SO2_Disabilities & $\begin{array}{l}\text { People with cognitive and } \\
\text { intellectual disabilities }\end{array}$ & Central Region & $>400$ & $1970 \mathrm{~s}$ \\
\hline $\mathrm{SO}_{3}$ FoodAlergies & People with food allergies & Lisbon Region & $0-100$ & $2000 \mathrm{~s}$ \\
\hline $\mathrm{SO}_{4}$ _SeniorUniversity & Seniors & Central Region & $0-100$ & $2000 \mathrm{~s}$ \\
\hline SO5_Disabilities & Deaf people & North Region & $>400$ & $1990 \mathrm{~s}$ \\
\hline SO6_Disabilities & $\begin{array}{l}\text { People with cognitive and } \\
\text { intellectual disabilities }\end{array}$ & North Region & $>400$ & $1970 \mathrm{~s}$ \\
\hline SO7_Disabilities & Blind or low-vision people & Central Region & $301-400$ & $1990 s$ \\
\hline SO8_Disabilities & Deaf people & Central Region & $201-300$ & $2000 \mathrm{~s}$ \\
\hline SO9_SeniorUniversity & Seniors & Central Region & $0-100$ & $2000 \mathrm{~s}$ \\
\hline
\end{tabular}


The role of social organisations in the promotion of recreation and tourism activities for people with special needs

\begin{tabular}{|c|c|c|c|c|}
\hline SO code & Type of PwSN & NUTS II & $\begin{array}{l}\text { № of } \\
\text { associates }\end{array}$ & $\begin{array}{l}\text { Decade of } \\
\text { foundation }\end{array}$ \\
\hline SO10_Disabilities & $\begin{array}{l}\text { People with cognitive and } \\
\text { intellectual disabilities }\end{array}$ & Central Region & $0-100$ & $1970 \mathrm{~s}$ \\
\hline SO11_Disabilities & Blind or low-vision people & Central Region & $0-100$ & * \\
\hline SO12_Disabilities & $\begin{array}{l}\text { People with cognitive and } \\
\text { intellectual disabilities }\end{array}$ & Central Region & $>400$ & $1980 \mathrm{~s}$ \\
\hline SO13_Senior & Seniors & Central Region & $0-100$ & $2000 \mathrm{~s}$ \\
\hline SO14_Disabilities & $\begin{array}{l}\text { People with physical } \\
\text { disabilities }\end{array}$ & Central Region & $0-100$ & $2000 \mathrm{~s}$ \\
\hline SO15_SeniorUniversity & Seniors & Central Region & $301-400$ & $2000 s$ \\
\hline SO16_SeniorUniversity & Seniors & Central Region & $101-200$ & $2000 \mathrm{~s}$ \\
\hline SO17_Disabilities & $\begin{array}{l}\text { People with cognitive and } \\
\text { intellectual disabilities }\end{array}$ & North Region & $0-100$ & $1970 \mathrm{~s}$ \\
\hline SO18_Disabilities & $\begin{array}{l}\text { People with cognitive and } \\
\text { intellectual disabilities }\end{array}$ & North Region & $>400$ & $1970 \mathrm{~s}$ \\
\hline SO19_FoodAllergies & People with food allergies & Central Region & $101-200$ & $1990 \mathrm{~s}$ \\
\hline SO2O_Disabilities & $\begin{array}{l}\text { People with cognitive and } \\
\text { intellectual disabilities }\end{array}$ & Central Region & $301-400$ & $1960 s$ \\
\hline SO21_Disabilities & $\begin{array}{l}\text { People with all types of } \\
\text { disabilities }\end{array}$ & Central Region & $0-100$ & $1980 \mathrm{~s}$ \\
\hline SO22_Disabilities & $\begin{array}{l}\text { People with all types of } \\
\text { disabilities }\end{array}$ & North Region & * & $2000 \mathrm{~s}$ \\
\hline SO23_Disabilities & Deaf people & Central Region & $201-300$ & $2000 \mathrm{~s}$ \\
\hline SO24_Disabilities & $\begin{array}{l}\text { People with all types of } \\
\text { disabilities or impairments }\end{array}$ & Lisbon Region & $>400$ & $1970 \mathrm{~s}$ \\
\hline SO25_Disabilities & $\begin{array}{l}\text { People with physical } \\
\text { disabilities }\end{array}$ & Central Region & $>400$ & $1970 \mathrm{~s}$ \\
\hline SO26_Disabilities & Blind or low-vision people & Lisbon Region & $101-200$ & $2000 s$ \\
\hline SO27_Disabilities & $\begin{array}{l}\text { People with cognitive and } \\
\text { intellectual disabilities }\end{array}$ & Central Region & $101-200$ & $1970 \mathrm{~s}$ \\
\hline SO28_FoodAllergies & People with food allergies & Lisbon Region & $>400$ & $1990 \mathrm{~s}$ \\
\hline SO29_Disabilities & $\begin{array}{l}\text { People with physical } \\
\text { disabilities }\end{array}$ & Alentejo Region & $101-200$ & $2000 \mathrm{~s}$ \\
\hline SO3o_Disabilities & $\begin{array}{l}\text { People with physical } \\
\text { disabilities }\end{array}$ & Lisbon Region & * & $2000 \mathrm{~s}$ \\
\hline
\end{tabular}

Note: * Information not available.

What type of recreation and tourism activities are offered by SO?

In the present study, the majority of SO have already promoted recreation or tourism activities for their members $(85.71 \%)$. Most of these activities are of short duration (only one day), sporadic and take place mainly in Portugal (Table 2). It is interesting to observe that recreation activities of short duration prevail in the Portuguese SO context, similarly to what was found in the literature reviewed (Abraham et al., 2002; Hall \& Hewson, 2006; Melbøe \& Ytterhus, 2017; Verdonschot et al., 2009a, 2009b). 
Table 2. Duration and destination of trips organised by Portuguese SO

\begin{tabular}{llll}
\hline Duration and destination of trips & & $\mathbf{N}$ & $\mathbf{\%}$ \\
\hline \multirow{3}{*}{ Day trips } & Several & 6 & 30.00 \\
& Few & $\mathbf{1 4}$ & 70.00 \\
& Total & $\mathbf{2 0}$ & $\mathbf{1 0 0}$ \\
\hline \multirow{3}{*}{ Overnight trips } & Several & 5 & 41.67 \\
& Few & 7 & 58.33 \\
& Total & $\mathbf{1 2}$ & $\mathbf{1 0 0}$ \\
\hline \multirow{3}{*}{ Destinations of the trips } & Domestic & $\mathbf{2 0}$ & 83.33 \\
& International & 4 & 16.67 \\
& Total & $\mathbf{2 4}$ & $\mathbf{1 0 0}$ \\
\hline
\end{tabular}

The role of SO as promoters of recreation and tourism activities points to a paradigm shift where organisations start to recognise the importance of guaranteeing these activities to their associates as part of their rights. Some narratives confirm this change and that $\mathrm{SO}$ usually consider the right of access to culture in their activity planning and develop strategies to respond properly to this: "Based on the right of access to culture, pertinent strategies were outlined for the operationalisation of activities to overcome the exclusion and physical inactivity of PwD" [SO25_Disabilities]. However, intrapersonal, interpersonal and structural constraints still affect the participation and preferences of PwSN, inhibiting their individual or in-group experiences (Crawford \& Godbey, 1987), as the present study demonstrates. Individual and group characteristics, as well as the characteristics of the environment are important aspects when SO select the type of experiences that they will offer. Therefore, the activities most frequently promoted by SO are excursions/tours (e.g. visiting Serra da Estrela, Fátima, House of Amália) (41.67\%), cultural visits (e.g. visits to museums, monuments, city tours) $(20.83 \%)$ and vacation colonies/holiday camps (16.67\%) (Table 3). Other types of activities are also organised, but not as frequently as the previous ones.

Table 3. Type of trips organised by Portuguese SO

\begin{tabular}{ll}
\hline Types of trips & $\%$ \\
\hline Excursions/Tours & 41.67 \\
Cultural visits & 20.83 \\
Vacation colonies/Holiday camps & 16.67 \\
Going to the beach & 12.50 \\
Sports activities & 12.50 \\
Encounters/Meetings with other PwD and their families & 4.17 \\
Events for socializing & 4.17 \\
Encounters with members of other institutions & 4.17 \\
Visiting caves & 4.17 \\
Visiting gardens & 4.17 \\
\hline
\end{tabular}

It is also important to note that the types of activities are strategically chosen to avoid possible constraints. The narratives emphasised that day trips prevent constraints with the accommodation and restaurant sectors, and that holiday camps are a safer choice for groups with special needs, as explained by the interviewees:

We do excursions. We take a tour during a day, visit museums... last year we went to see Amália's house... [...] Many hotels do not want to let a guide dog in. [SO7_Disabilities] 
We always have to know, at each moment, where we are going to be because we imagine that we are not able to cook or to take [food] for a whole day ... we always take food with us! [SO3_FoodAllergies]

Every year, our associates go on a summer camp for a week, with the supervision of the monitors. [...] We never get into a normal hotel... we are afraid of the hotels; we need a lot of supervision for these groups to include them in the hotels. [SO2O_Disabilities]

As the previous discourses show, the planning of these activities shows SO's pro-active posture, which has great benefits for all parties involved, as can be observed in the next section.

Why do SO provide recreation and tourism activities?

When the interviewees were asked why the SO provide recreation and tourism activities, all the interviewees answered that participation in this kind of activities greatly increases the well-being and quality of life of all PwSN and their families. All emphasised that the opportunity of participating in new experiences and activities positively influences the lives of PwSN, leading to improvements in physical and emotional well-being of participants, as described in the following quotes:

Happiness, satisfaction... even hygiene benefits... because to leave the house, they already have to take a bath, they have to get dressed. If they are at home all day, they will be in their housecoats. Maybe they will not even eat an adequate meal ... [SO__SeniorUniversity]

Happiness and new memories. They come fresher, with more energy, and want to tell what they have experienced. [SO9_SeniorUniversity]

Many positive changes are observed in their emotional state. This change is due to the few opportunities that they have enjoyed throughout their lives. There are many who have never left their community, except with the institution to which they are linked. [SO25_Disabilities]

The benefits for PwSN most emphasised by SO, presented in Table 4, are: providing new opportunities and horizons through new activities outside the institutions' facilities; promoting individual development and independency from their families; and promoting participation and social integration in the community. Despite the importance of participating in these activities for all PwSN, most SO recognise that this is especially relevant for those individuals who do not have opportunities to carry out experiences without the support of SO, as observed in the following discourse: "There is a lack of moments of leisure, holidays. Financial difficulties, accessibility, among others are diagnosed as difficulties to experience activities of this nature" [SO26_Disabilities]. The family context and especially contexts of economic disadvantage emerged as important inhibitors in the participation in recreation and tourism activities, highlighting the importance of $\mathrm{SO}$ as promoters of these activities.

Table 4. Why Portuguese SO organize recreation and tourism activities

\begin{tabular}{ll}
\hline Benefits for PwSN & $\%$ \\
\hline Get out of their spaces/routines & 16.67 \\
Do different things/have new experiences & 16.67 \\
Allow caregivers to rest/have a moment just for themselves & 12.50 \\
Promoting participation and integration in the community & 8.33 \\
Being with other people & 4.17 \\
Doing outdoor activities & 4.17 \\
\hline
\end{tabular}


These data are interesting and can explain the investment and efforts in the promotion of this type of activities by organisations that are not specialised in this area. This attitude is especially remarkable when considering the constraints faced by these organisations in promoting these activities.

Which constraints do SO face in organising recreation and tourism activities?

Despite the benefits that PwSN obtain from the recreational and tourism activities promoted by SO, these organisations face various difficulties in planning and implementing these activities. $92 \%$ of interviewees stated that they find many difficulties in the promotion of recreation and tourism activities and identify mostly external constraints (environmental and interactive) as the reasons for these difficulties. Lack of accessibility of tourism products emerge as the most emphasised constraint across all narratives, being reflected in different ways (Table 5). In this context, some interviewees mention the cultural sector: "We went to the [name of the museum] museum... and the women [from the front desk] told me: "we don't have access ramps; we don't have an elevator" [SO13_Seniors]. Another interviewee highlights the prevalence of inaccessibility as a structural problem already faced in "countless places", as is visible in the following discourse:

We face countless places that do not comply with the law of accessibility, or the rights of PwD. We note the lack of knowledge on the part of the entities when asked about accessibility issues. [SO2O_Disabilities]

However, lack of accessibility goes beyond mobility, also including access to information and communication. SO which represent people with sensory disabilities (e.g. blind, low vision and deaf), highlight numerous and persistent communication barriers (e.g. lack of visual or audio accessible information). On the other hand, SO working with people with intellectual disabilities focus on the importance of alternative communication that can make access to information easier for everyone.

The great barrier for the deaf community is the communication barrier [...]. Sometimes people think: "They can write, but there are many deaf people who do not speak Portuguese, do not understand what is written, nor do they know how to write ... [INS8_Disabilities].

[There is an] absence of information in accessible formats: Braille, audio description, touch samples, sign language interpreter, tactile maps of the space. [SO25_Disabilities]

They don't often have the capacity to go to a museum and see a collection... it doesn't mean anything to them ... if they went to see a Mona Lisa, it doesn't mean anything to them, either they like to see it or not. Even the explanations [in guided tours] should be much simpler. They should explain it in a way they understand. A guide has to know how to explain it in a totally different way ...[SO2_Disabilities]

These constraints bring several challenges which are of relevance to recreation and tourism suppliers, not only to offer information concerning the accessibility of their products, but also to do it in an accessible way, directing their communication strategies according to the needs of these groups.

The lack of accessibility compromises the choice and participation of PwSN in recreation and tourism activities. Interviewees also reported other difficulties in this scope, such as the following: "Finding a place that guarantees compliance with all necessary procedures to ensure that the users' meals are glutenfree, without risk of contamination." [SO28_FoodAllergies]. One of the main problems related to the lack of accessibility is the non-compliance with the legislation. 
Besides the lack of physical and informational accessibility, other constraints were identified, such as the lack of financial resources, reported by $16.67 \%$ of the interviewees. Activities have costs, in most cases, and PwSN and their families do not have financial capacity to fund these experiences. In addition, Portuguese SO do not have sufficient financial resources to support these activities either. In disadvantaged economic and social contexts, the chances of some persons with disabilities to participate in this type of experiences without the support of SO is almost null, as one interviewee stated:

All this [participation in activities or not] is related to the family's economic power. There are people who are going on vacation, who have money, who are going to do many things and take their children ... but in the case of most users, the families' economic situation is very fragile and they have no ability to go [on vacations] without the institution support. [SO2_Disabilities]

Without financial resources, SO do not have the capacity to promote certain activities: "We asked for a quota to fund leisure activities, but the values were very expensive and then the associates started to say that it was too expensive for them and the association could not pay that value" [SO8_Disabilities]. Accessibility and financial constraints are also the most emphasised constraints by PwD in recreation and tourism experiences, as other studies point out (e.g. Freeman \& Selmi, 2010; Yau et al, 2004).

This study also identifies other constraints, such as lack of knowledge and attitudes of providers (see Table 5). The prevalence of attitudinal barriers is often associated with social prejudice and the prevalence of social stereotypes (Aiden \& McCarthy, 2014; Devile \& Kastenholz, 2018), which is corroborated by a SO interviewee:

Lack of knowledge combined with fear, lack of training and prejudice are factors that most often reflect the behaviour of professionals [tourism sector professionals]. The disabled person, unfortunately, even today, is seen as someone incapable based on a historical tradition of difference and inequality. [SO26_Disabilities]

Table 5. Constraints that Portuguese SO face in organising recreation and tourism activities

\begin{tabular}{llc}
\hline Type of constraints & & \% \\
\hline Physical accessibility & $\begin{array}{l}\text { Lack of accessibility in: transport; restaurants; accommodation; } \\
\text { museums and other tourist attractions; public space; tourism } \\
\text { destinations }\end{array}$ & 33.34 \\
\hline Financial resources & Lack of financial resources & $\mathbf{1 6 . 6 7}$ \\
\hline $\begin{array}{l}\text { Knowledge about the } \\
\text { market }\end{array}$ & $\begin{array}{l}\text { Lack of knowledge about the needs of PwSN } \\
\text { Lack of restaurants prepared to receive people with food allergies }\end{array}$ & $\mathbf{1 2 . 5 1}$ \\
\hline Communication & $\begin{array}{l}\text { Lack of communication in Portuguese sign language (deaf); } \\
\text { difficulties in communicating in an accessible way }\end{array}$ & 8.34 \\
\hline Rules and regulations & Barriers to using guide dogs & 4.17 \\
\hline Human resources & $\begin{array}{l}\text { Lack of human resources in SO to plan and organize recreation and } \\
\text { tourism experiences }\end{array}$ & 4.17 \\
\hline Group heterogeneity & In SO individuals have different special needs & 4.17 \\
\hline Attitudes of providers & Unhelpful attitude to receive groups of PwSN & 4.17 \\
\hline $\begin{array}{l}\text { Family and domestic } \\
\text { context }\end{array}$ & $\begin{array}{l}\text { Difficulties in engaging in activities and leaving home (domestic } \\
\text { responsibilities) }\end{array}$ & 4.17 \\
\hline
\end{tabular}


The type of barrier previously mentioned is especially identified in interactions with others outside the SO's facilities: "There is a little bit of discrimination ... in some places ... even in the way of communicating, people are a little bit ruder" [SO4_SeniorUniversity]. In addition, the lack of specialised human resources in SO to plan and organize recreation and tourism experiences was also identified as a constraint to develop this kind of activities as can be seen in the following discourse:

I can never take many wheelchairs [users of wheelchairs on the trips organised], because I don't have specialised human resources to do the accompaniment or, also, the bus doesn't have many seats ... [SO11_Disabilities]

\section{Which strategies do SO use to plan recreation and tourism activities?}

Due to the significant constraints that SO face in providing recreation and tourism activities to their members, they use some coping strategies to plan these activities (Table 6).

Table 6. Strategies adopted by Portuguese SO to plan recreation and tourism activities

\begin{tabular}{ll}
\hline Strategies & $\%$ \\
\hline $\begin{array}{l}\text { Multiple contacts with supply agents to obtain detailed information } \\
\text { (by email or phone) }\end{array}$ & 37.50 \\
\hline $\begin{array}{l}\text { Use of multiple information sources such as Internet, accessible tourism pages, web pages } \\
\text { and other platforms (e.g. booking) }\end{array}$ & 20.67 \\
\hline Use of own knowledge & 16.67 \\
\hline Planning and taking many details into account & 12.50 \\
\hline Use of site reconnaissance trips & 8.33 \\
\hline Use of travel agencies and other types of institutions that organize trips & 8.33 \\
\hline Use of volunteers who organize these trips & 4.17 \\
\hline
\end{tabular}

Concerning the planning process of activities outside their facilities, SO point out quality of the available information as one of the main causes for the persistence of many constraints. The interviewees reveal that negative past experiences led SO to be suspicious about the accessibility of places, products, and the real conditions of services. As one of the interviewees revealed, it is quite usual to receive untrustworthy information when planning a trip, which affects the quality of their associates' experience and mobility. For example, an interviewee said: "Many times, they say it [accommodation] is adapted but then the bathroom is so small that it does not allow a wheelchair to move around" [SO3O_Disabilities].

Moreover, these negative experiences also led SO to combine traditional approaches (phone, personal contacts) with modern ones (searching on the Internet, web pages, and other online platforms), in their research and planning of recreation and tourism activities, as is evident in their narratives:

We call beforehand to understand the real conditions [of the places, services] ... so that afterwards, they [associates] know in advance what they can count on, or not. [SO9_Senioruniversity]

[If I know] someone who has already gone there, I ask the person directly... [Then] I research, I call... I prefer to make phone calls. I also like to go on the Internet [research], but to confirm I always like to call... [SO12_Disabilities] 
They prefer direct contact (phone and e-mail) with supply agents to avoid negative impacts. For 37.5\% of the organisations, making a phone call or sending an email is the only way to obtain detailed information and check the conditions of service providers, and to ensure that their associates will "have a good stay". As interviewees stated:

We usually even get in touch to find out if everything exists, what does not exist, what to bring ... to better understand if we can have a good stay. [SO__Disabilities]

We use web pages and platforms, such as Booking. Also, accessible tourism web pages, which, in my view, are also not very objective and enlightening and have wrong information about the places. We use telephone contact. [SO26_Disabilities]

We look in advance at which restaurants and hotels offer safe, gluten-free meals, whether planning a day trip or an overnight stay. [SO28_FoodAllergies]

For the majority of SO, the information provided by supply agents is not accessible, updated or reliable. Because of that, SO do not trust in the information provided by supply agents, especially through websites and other online platforms. Some interviewees also referred to relying on their own knowledge, doing site reconnaissance trips, using other organisations such as travel agencies or accepting the help of volunteers, as can be observed in the following discourses:

We went to [name of bathing site], half associates and half volunteers. Each of the associates had a sponsor [a volunteer].... The sponsor was responsible for the food, hygiene and slept in the same tent [of the associate]. [SO1_Disability]

Whenever we didn't want to take risks, someone technically equipped would recognise the site... [SO6_Disability]

I plan [the trip] with the help of [name of travel agency]. I say: I would like to do a trip to Ireland, or I want a tour trip, and we don't want to get up too early, because seniors don't like to get up too early, and there's a lot of care with the food [dietary restrictions] and the meals have to be all inclusive. With [name of travel agency] the trips are a rest. Everything is taken with care. [SO15_Senioruniversity]

Which strategies can be used to improve the role of SO in the development of accessible tourism? Considering the planning process that SO adopt, as well as all the constraints and difficulties they face during this process, these organisations identify strategies that can improve their role in the organisation of recreation and tourism activities and consequently increase the participation of PwSN in these activities.

One of the strategies identified is to increase the supply of social recreation and tourism activities, which are provided free of charge to PwSN. Most SO identify economic factors as one of the constraints on PwSN participating in these activities. In contexts where the levels of social inequalities are very high, like the Portuguese context (Carmo et al., 2018), social tourism initiatives are a good strategy to increase the participation of social and economically disadvantaged groups in tourism. The benefits of this type of initiatives are huge, with a positive impact for all parties involved: participants, organizations, destination communities and the whole of society (Eusébio et al., 2016). Considering the data obtained, it is possible to conclude that $\mathrm{SO}$ already provide social tourism initiatives, according to the principles of the European Economic and Social Committee (EESC, 2014) and these organisations argue that it is 
important to increase the supply of these initiatives, since they are often the only way for PwSN to have the opportunity to participate in recreation and tourism activities and to reduce their isolation. The following testimonies are good examples of the relevance assigned to social initiatives:

(...) their parents never got out of here [community] and we are providing things ... new horizons... so that they enjoy life, they do different things and when they arrive, they feel valued ... [SO2_Disabilities]

The [name of SO] aims to organise and develop actions that allow the clients to actively participate in the community, in contrast to the trend of isolation and social exclusion. It promotes the full integration into society of people with disabilities, allowing for awareness of equality with regard to their dignity and rights as citizens. Based on the right to access culture, pertinent strategies were designed for the operationalisation of activities to overcome the exclusion and physical inactivity of people with disabilities. [SO25_Disabilities]

Taking into account the financial difficulties of SO already mentioned, these organisations use networking with other entities to obtain external support, either financial or free services. These networks are crucial to intensify the role of these organisations as can be observed in the following statements:

The service was contracted with all included at the [name of institution]. It has vacation packages for people with [...]. The INR [National Rehabilitation Institute] paid the daily rate and the parish council paid for the transport. [SO17_Disabilities]

We hold national meetings for people with disabilities and their families across the country. This year it was in [city name], and two years ago, it was in [city name] [...] We depend on state support, then we request the support from the municipalities that "give" us the auditoriums, free of charge ... private companies that help us ... with the costs of these meetings. [SO21_Disabilities]

The interviewees also found important to involve human resources in the overall process of organising recreation and tourism activities. Findings evidence that without the efforts of SO workers and volunteers, many PwSN would never have had a recreation or tourism experience in their lives. Due to the special needs of their associates, in most SO human resources are responsible for identifying possible constraints and making all the arrangements: transportation, accommodation, experiences (like tours, or other activities), and food. To ensure that everything goes as planned, human resources usually contact supply agents directly to obtain detailed information about products and services and, in some cases, even make site inspection trips to check accessibility conditions. The following testimonies are good examples of the involvement of the human resources:

When we take people in a wheelchair, then we have to think about their disability ... we have to see if there is accessibility, what is the accessibility that exists, if the room is accessible or what is the possibility of it being accessible ... if the bathrooms are accessible, if you can bathe easily in the place where you bathe. [SO2_Disabilities]

When we are organising events ... we visit the hotels, we visit the sports facilities and we assess the accessibility... [SO14_Disabilities]

Planning and organisation of recreation and tourism activities are often not only carried out by the SO staff, as well as with the support of volunteers. Volunteers are very important in supporting the SO's 
work, performing activities and tasks inside and outside the organisations. SO take advantage of volunteers' support and give them functions according to their profile and capacities. Some interviewees also reveal that they train volunteers to perform direct support tasks and help their associates during the activities organised, as can be observed in the following testimonies:

We have to train the volunteers about [associates] needs (...) when we go as a group it is easier because we have volunteers. We also went camping with them ... we went to [name of place]... half associates and half volunteers. [SO1_Disabilities]

We have a volunteer here with us (...) She is a retired teacher .... She ends up organising our trips and being our guide ... we are the back office a little bit and we select the participants ... She tells us: this trip has $x$ places; let's go here; do you like this itinerary? This volunteer... She [is responsible for this and] recognises the route... the route is done... and we choose the route already according to the people we think will want to go... [SO13_Seniors]

Concerning the accessibility of the tourism industry, this study highlights many constraints, with SO doing tremendous work in order to make recreation and tourism accessible for all, but also stressing the need for tourism suppliers to provide more information about the accessibility of the tourism industry in an accessible way. Some results indicate that SO search for and provide accessible information and information about the level of accessibility. This information can be used to meet the needs of associates and their families and, at the same time, it fulfils the needs of the rest of this market segment. The findings also show that SO can contribute to the elimination of physical and attitudinal barriers by sharing their knowledge, as may be observed in some discourses:

I notice that there is embarrassment there, because people do not have contact with this type of population, but I do not even take it the wrong way. However, despite the good will they have, they do not know how to deal with this. It is not that they do not want to do it and sometimes they commit the "sin" of excess [do many things] and do not focus on what is essential, but they do not know what is essential... [SO22_Disabilities]

There is still a long way to go ... it is a big change in mentality to make everything accessible. People in hotels, in restaurants and so on must know how to act when they receive a person with some kind of disability... [SO3O_Disabilities]

The presence of SO and their associates in different contexts can have positive effects on the tourism industry, namely in the sensitivity and attitudes of service providers. Regular contact with this market can change the attitudes, improving the performance regarding the customer service, and the experience of all parties involved.

\section{Conclusion and implications}

The findings of this study underline a dynamic and pro-active approach of social organisations in the promotion of recreation and tourism activities for their associates. This paper provides important theoretical contributions. First, it enables to get insights into the constraints that SO experience when organising recreation and tourism activities to $\mathrm{PwSN}$, which are also highly related to the factors that most limit the participation of these people in recreation and tourism. The prevalence of multiple constraints is recognised, especially structural ones, comprising the lack of physical accessibility in the tourism industry (Crawford \& Godbey, 1987; Devile \& Kastenholz, 2018; Nyaupane \& Andereck, 2008), the lack of accessible information (Michopoulou \& Buhalis, 2013); lack of products and services suitable 
to the needs of PwSN (Porto et al., 2019), and inappropriate attitudes of staff (Aiden \& McCarthy, 2014; Devile \& Kastenholz, 2018), among others. These constraints affect the operation of SO, including the type and duration of the activities organised by these organisations, with the most common activities being recreation activities occurring in the course of one day, sporadically and in the country of residence.

Second, the present paper extends the limited and fragmented literature (Blichfeldt \& Nicolaisen, 2011; Hunter-Jones, 2011; Loi \& Kong, 2015) concerning SO’s functions in understanding the role of SO as organisers of recreation and tourism activities. Besides all the constraints and difficulties, findings show the great efforts that SO put into this organisation, as a consequence of recognising the importance of the participation of their associates in this kind of activities. Results suggest that the recreation and tourism activities organised by $\mathrm{SO}$ are often the only opportunity that many PwSN have to participate in this kind of activities and this participation greatly contributes to increasing the physical and emotional well-being of PwSN, especially those coming from disadvantaged backgrounds. The promotion of these activities by SO results from a careful planning process which is very dependent on direct contacts with supply agents, in order to overcome the constraints identified above. SO have to overcome many difficulties arising when organising these activities, such as the lack of knowledge of service providers about the characteristics and necessities of PwSN, the lack of available information concerning the accessibility of tourism destinations and products, the lack of accessibility of touristic facilities and the low financial resources of the SO themselves.

Third, this research also permits the identification of the strategies adopted by SO to plan recreation and tourism activities and to increase the level of participation of their associates in those activities. Besides often relying on their own knowledge and on the information obtained from direct contacts with service providers, as already mentioned, representatives of SO also do site reconnaissance trips. In addition, they carefully select types of accommodations (e.g. holiday camps) and activities (e.g. cultural visits, sport activities and activities involving socialisation) which are more appropriate for their associates. Moreover, in order to overcome problems related to limited financial and human resources, $\mathrm{SO}$ also create networks with several entities in order to have access to funds and obtain free services, and also try to get the cooperation of volunteers, sometimes providing them training.

Additionally, this study also provides important practical contributions for many people and entities, including tourism supply agents and SO. First, results show the importance of supply agents obtaining more knowledge and improving the physical accessibility of their facilities. Second, it also reveals the relevance of supply agents providing accessible, updated and reliable information about their services and products, especially on online platforms, to increase SO's trust in supply agents. Third, this research is especially important to identify strategies already adopted by some SO and that may be used by many other organisations that work with PwSN, which include, among many others: the selection of alternatives to the traditional types of accommodation; site inspection trips; direct contact with supply agents to obtain more detailed information, namely regarding accessibility; cooperating with volunteers and sometimes training them; networking with other entities to obtain some support. Fourth, this paper also highlights the need for SO to create good connections with existing entities and take advantage of the available initiatives and financial instruments to ensure funding, due to their usual low financial resources. In this scope, it is very important for SO to convince tourism supply agents and other entities of the advantages of (direct or indirect) investing in their initiatives.

Despite the significant contributions of this study, it is only an exploratory study undertaken in just one country. Therefore, more studies should be carried out on this topic in other countries, to see whether 
similar results are obtained or if different insights emerge which complement this study. Furthermore, the present study only relied on interviews with SO to evaluate their role. Further research involving interviews and questionnaires with PwSN would also be very important to obtain their perspective about the role of SO. Finally, this research selected the SO based on a web search, which may have excluded SO without an online presence. Thus, future research should extend the sample selection to SO with no online presence. All this research would be very important to increase knowledge in accessible tourism and to make recreation and tourism activities accessible for all.

\section{Acknowledgments}

This work was financially supported by the project POCI-01-0145-FEDER-030376, funded by FEDER, through COMPETE2ozo - Programa Operacional Competitividade e Internacionalização (POCI), and by national funds (OE), through FCT/MCTES.

\section{References}

Abraham, C., Gregory, N., Wolf, L., \& Pemberton, R. (2002). Self-esteem, stigma and community participation amongst people with learning difficulties living in the community. Journal of Community \& Applied Social Psychology, 12(6), 430-443. https://doi.org/10.1002/casp.695

Adalbert, E., \& Laville, J.-L. (2004). Defining the Third Sector in Europe. In E. Adalbert \& J.-L. Laville (Eds.), The Third Sector in Europe. Edward Elgar.

Ager, A., Myers, F., Kerr, P., Myles, S., \& Green, A. (2001). Moving Home: Social Integration for Adults with Intellectual Disabilities Resettling into Community Provision. Journal of Applied Research in Intellectual Disabilities, 14(4), 392-400. https://doi.org/10.1046/j.1468-3148.2001.00082.x

Aiden, H., \& McCarthy, A. (2014). Current attitudes towards disabled people. Scope. Retrieved from: http://www.scope.org.uk/About-Us/Media/Press-releases/May-2014/New-research-Majority-ofBritsuncomfortable-talki

Allan, M. (2015). Accessible tourism in Jordan: travel constrains and motivations. European Journal of Tourism Research, 10, 109-119.

Alves, J. P. (2016). Cuidar e ser cuidado: Uma análise do cuidado quotidiano, permanente e de longa duração. University of Coimbra.

Ashman, A. F., \& Suttie, J. N. (2007). The social and community involvement of older Australians with intellectual disabilities. Journal of Intellectual Disability Research, 40(2), 120-129. https://doi.org/10.1046/j.1365-2788.1996.719719.x

Badia, M., Longo, E., Orgaz, M. B., \& Gómez-Vela, M. (2013). The influence of participation in leisure activities on quality of life in Spanish children and adolescents with Cerebral Palsy. Research in Developmental Disabilities, 34(9), 2864-2871. https://doi.org/10.1016/j.ridd.2013.06.017

Barnett, J., Botting, N., Gowland, M. H., \& Lucas, J. S. (2012). The strategies that peanut and nut-allergic consumers employ to remain safe when travelling abroad. Clinical and Translational Allergy, 2(1), 17. https://doi.org/10.1186/2045-7022-2-12

Bauer, I. (2018). When travel is a challenge: travel medicine and the 'dis-abled' traveller. Travel Medicine and Infectious Disease, 22, 66-72. https://doi.org/10.1016/j.tmaid.2018.02.001

Beart, S., Hawkins, D., Kroese, B. S., Smithson, P., \& Tolosa, I. (2001). Barriers to accessing leisure opportunities for people with learning disabilities. British Journal of Learning Disabilities, 29(4), 133138. https://doi.org/10.1046/j.1468-3156.2001.00109.x

Bedini, L. A., \& Phoenix, T. L. (1999). Addressing Leisure Barriers for Caregivers of Older Adults: A Model Leisure Wellness Program. Therapeutic Recreation Journal, 33(3), 222-240. 
Bergier, J., Dąbrowski, D., \& Żbikowski, J. (2011). Conditioning of participation of disabled males and females from eastern regions of Poland in tourism and recreation. Annals of Agricultural and Environmental Medicine, 18(2), 350-354.

Blichfeldt, B., \& Nicolaisen, J. (2011). Disabled travel: not easy, but doable. Current Issues in Tourism, 14(1), 79-102. https://doi.org/10.1080/13683500903370159

Capucha, L., Aires, S., Quintela, J., Reis, A., \& Santos, P. (1995). ONG's de Solidariedade: práticas e disposições (REAPN (ed.)).

Card, J., Cole, S., \& Humphrey, A. (2006). A comparison of the accessibility and attitudinal barriers model: travel providers and travelers with physical disabilities. Asia Pacific Journal of Tourism Research, 11(2), 161-175. https://doi.org/10.1080/10941660600727566

Carmo, R., Sebastião, J., Azevedo, J., Martins, S., \& Costa, M. (2018). Desigualdades Sociais. Portugal e a Europa (Issue March). Mundos Sociais.

Commission, E. (2007). Special Eurobarometer Health and long-term care in the European Union.

Comstock, S. S., DeMera, R., Vega, L. C., Boren, E. J., Deane, S., Haapanen, L. A. D., \& Teuber, S. S. (2008). Allergic reactions to peanuts, tree nuts, and seeds aboard commercial airliners. Annals of Allergy, Asthma and Immunology, 101(1), 51-56. https://doi.org/10.1016/S1081-1206(10)60835-6

Constantinou, V., Loizides, F., \& Ioannou, A. (2016). A personal tour of cultural heritage for deaf museum visitors. In M. Ioannides et al. (Eds.), Digital Heritage. Progress in Cultural Heritage: Documentation, Preservation, and Protection. (pp. 214-221). Springer, Cham. https://doi.org/10.1007/978-3-319-48974-2

Crawford, D. W., \& Godbey, G. (1987). Reconceptualizing barriers to family leisure. Leisure Sciences, 9(2), 119-127. https://doi.org/10.1080/01490408709512151

Crawford, D. W., Jackson, E. L., \& Godbey, G. (1991). A hierarchical model of leisure constraints. Leisure Sciences, 13(4), 309-320. https://doi.org/10.1080/01490409109513147

Daniels, M., Rodgers, E., \& Wiggins, B. (2005). “Travel Tales”: an interpretive analysis of constraints and negotiations to pleasure travel as experienced by persons with physical disabilities. Tourism Management, 26(6), 919-930. https://doi.org/10.1016/j.tourman.2004.06.010

Darcy, S., \& Dickson, T. (2009). A whole-of-life approach to tourism: the case for accessible tourism experiences. Journal of Hospitality and Tourism Management, 16(1), 32-44. https://doi.org/10.1375/jhtm.16.1.32

Darcy, S., McKercher, B., \& Schweinsberg, S. (2020). From tourism and disability to accessible tourism: a perspective article. Tourism Review, 75(1), 140-144. https://doi.org/10.1108/TR-07-2019-0323

Decree-law. (n.d.-a). Decreto-Lei n. ${ }^{\circ}$ 106/2013, de 30 de julho.

Decree-law. (n.d.-b). Decreto-Lei ${ }^{\circ} 163 / 2006$ de 8 de Agosto.

Denscombe, M. (2007). The good research guide for small-scale socail research projects. Open University Press.

Devile, E., \& Kastenholz, E. (2018). Accessible tourism experiences: the voice of people with visual disabilities visual disabilities. Journal of Policy Research in Tourism, Leisure and Events, 10(3), 265285. https://doi.org/10.108o/19407963.2018.1470183

Diekmann, A., \& McCabe, S. (2011). Systems of social tourism in the European Union: a critical review. Current Issues in Tourism, 14(5), 417-430. https://doi.org/10.108o/13683500.2011.568052

Eichhorn, V., Miller, G., \& Tribe, J. (2013). Tourism: a site of resistance strategies of individuals with a disability. Annals of Tourism Research, 43, 578-60o. https://doi.org/10.1016/j.annals.2013.03.006

Eisenberg, Y., \& Maisel, J. (2021). Environmental Contexts Shaping Disability and Health. In D. J. Lollar, W. Horner-Johnson, \& K. Froehlich-Grobe (Eds.), Public Health Perspectives on Disability (pp. 107128). Springer US. https://doi.org/10.1007/978-1-0716-o888-3_5 
European Economic and Social Committee EESC. (2014). Opinion of the European Economic and Social Committee on 'EU-Morocco Trade Relations.' Retrieved from: http://eur-lex.europa.eu/LexUriServ/ LexUriServ.do?uri=OJ:C:2009:077:0109:01:en:HTML

Eusébio, C., Carneiro, M. J., Kastenholz, E., \& Alvelos, H. (2016). The impact of social tourism for seniors on the economic development of tourism destinations. European Journal of Tourism Research, 12, $5^{-}$ 24.

Evcil, A. (2018). Barriers and preferences to leisure activities for wheelchair users in historic places. Tourism Geographies, 20(4), 698-715. https://doi.org/10.108o/14616688.2017.1293721

Ferreira, S. (2009). Terceiro Setor. In A. Cattani, L. I. Gaiger, P. Hespanha, \& J. L. Laville (Eds.), Dicionário Internacional da Outra Economia (pp. 322-328). Coimbra: Almedina.

Figueiredo, E., Kastenholz, E., \& Eusébio, C. (2012). How diverse are tourists with disabilities? A pilot study on accessible leisure tourism experiences in Portugal. International Journal of Tourism Research, 14, 531-550. https://doi.org/10.1002/jtr

Franco, R., Sokolowski, S. W., Hairel, E. M. H., \& Salamon, L. M. (2005). O sector não lucrativo Português: uma perspectiva comparada. Universidade Católica Portuguesa / John Hopkins University.

Freund, D., Cerdan Chiscano, M., Hernandez-Maskivker, G., Guix, M., Iñesta, A., \& Castelló, M. (2019). Enhancing the hospitality customer experience of families with children on the autism spectrum disorder. International Journal of Tourism Research, 21(5), 606-614. https://doi.org/10.1002/jtr.2284

Froehlich-Grobe, K., Douglas, M., Ochoa, C., \& Betts, A. (2021). Social Determinants of Health and Disability. In D. J. Lollar, W. Horner-Johnson, \& K. Froehlich-Grobe (Eds.), Public Health Perspectives on Disability (pp. 53-89). Springer US. https://doi.org/10.1007/978-1-0716-o888-3_3

Gassiot, A., Prats, L., \& Coromina, L. (2018). Tourism constraints for Spanish tourists with disabilities: Scale development and validation. Documents d'Anàlisi Geogràfica, 64(1), 49-71. https://doi.org/10.5565/rev/dag.364

Gillovic, B. (2019). Experiences of care at the nexus of intellectual disability and leisure travel. University of Waikato.

Goodhead, A., \& Mcdonald, J. (2007). Informal Caregivers Literature Review A report prepared for the National Health Committee. Health Services Centre, Victoria University of Wellington.

Griffin, K., \& Stacey, J. (2011). Towards a 'tourism for all' policy for Ireland: achieving real sustainability in Irish tourism. Current Issues in Tourism, 14(5), 431-444. https://doi.org/10.1080/13683500.2011.568053

Hall, L., \& Hewson, S. (2006). The Community Links of a Sample of People with Intellectual Disabilities. Journal of Applied Research in Intellectual Disabilities, 19(2), 204-207. https://doi.org/10.1111/j.14683148.2005.00249.X

Henderson, K. A., Bedini, L. A., Hecht, L., \& Schuler, R. (1995). Women with physical disabilities and the negotiation of leisure constraints. Leisure Studies, 14(1), 17-31. https://doi.org/10.1080/02614369500390021

Hersh, M. A. (2016). Improving Deafblind Travelers' Experiences: An International Survey. Journal of Travel Research, 55(3), 380-394. https://doi.org/10.1177/0047287514546225

Hunter-Jones, P. (2011). The role of charities in social tourism. Current Issues in Tourism, 14(5), 445-458. https://doi.org/10.108o/13683500.2011.568054

INE. (2012). Resultados Definitivos. In Censos 2011 (Vol. 26). https://censos.ine.pt/xportal/xmain?xpid=CENSOS\&xpgid=ine_censos_publicacao_det\&contexto= pu\&PUBLICACOESpub_boui=73212469\&PUBLICACOESmodo=2\&selTab=tab1\&pcensos=61969554.

INE. (2019). Conta Satélite da Economia Social. Retrieved from: https://www.ine.pt/xportal/ xmain?xpid=INE\&xpgid=ine_destaques\&DESTAQUESdest_boui=379958840\&DESTAQUESmodo=2 \&xlang=pt 
Innes, A., Page, S., \& Cutler, C. (2016). Barriers to leisure participation for people with dementia and their carers: an exploratory analysis of carer and people with dementia's experiences. Dementia, 15(6), 1643-1665. https://doi.org/10.1177/1471301215570346

Kanny, G. (2015). Impact of Food Allergies on the Allergic Person's Travel Decision, Trip Organization and Stay Abroad. Global Journal of Allergy, 1(2), 40-43. https://doi.org/10.17352/2455-8141.0000o9

Kastenholz, E., Eusébio, C., \& Figueiredo, E. (2015). Contributions of tourism to social inclusion of persons with disability. Disability and Society, 30(8), 1259-1281. https://doi.org/10.108o/o9687599.2015.1075868

Kim, S., \& Lehto, X. (2012). The voice of tourists with mobility disabilities: insights from online customer complaint websites. International Journal of Contemporary Hospitality Management, 24(3), 451-476. https://doi.org/http://dx.doi.org/10.1108/MRR-09-2015-0216

Kim, S., \& Lehto, X. (2013). Travel by families with children possessing disabilities: motives and activities. Tourism Management, 37, 13-24. https://doi.org/10.1016/j.tourman.2012.12.011

Lee, B., Agarwal, S., \& Kim, H. (2012). Influences of travel constraints on the people with disabilities' intention to travel: an application of Seligman's Helplessness theory. Tourism Management, 33, 569579. https://doi.org/10.1016/j.tourman.2011.06.011

Lehto, X., Luo, W., Miao, L., \& Ghiselli, R. (2018). Shared tourism experience of individuals with disabilities and their caregivers. Journal of Destination Marketing $\mathcal{E}$ Management, 8, 185-193. https://doi.org/10.1016/j.jdmm.2017.04.001

Loi, K. I., \& Kong, W. H. (2015). People with disabilities (PwD) in the tourism industry-concepts and issues. In Critical Tourism Studies Conference VI" 10 years CTS: Reflections on the road less travelled and the journey ahead", Opatija, Croatia, 26-30 June 2015. Critical Tourism Studies.

Lovelock, B. (2010). Planes, trains and wheelchairs in the bush: attitudes of people with mobilitydisabilities to enhanced motorised access in remote natural settings. Tourism Management, 31(3), 357-366. https://doi.org/10.1016/j.tourman.2009.03.014

McCabe, S., \& Diekmann, A. (2015). The rights to tourism: Reflections on social tourism and human rights. Tourism Recreation Research, 40(2), 194-204. https://doi.org/10.1080/02508281.2015.1049022

Melbøe, L., \& Ytterhus, B. (2017). Disability leisure: in what kind of activities, and when and how do youths with intellectual disabilities participate? Scandinavian Journal of Disability Research, 19(3), 245-255. https://doi.org/10.1080/15017419.2016.1264467

Mesquita, S., \& Carneiro, M. (2016). Accessibility of european museums to visitors with visual impairments. Disability \& Society, 31(3), 373-388. https://doi.org/10.108o/o9687599.2016.1167671

Michopoulou, E., \& Buhalis, D. (2013). Information provision for challenging markets: the case of the accessibility requiring market in the context of tourism. Information E Management, 50(5), 229-239. https://doi.org/10.1016/j.im.2013.04.001

Morgan, N., Pritchard, A., \& Sedgley, D. (2015). Social tourism and well-being in later life. Annals of Tourism Research, 52, 1-15. https://doi.org/10.1016/j.annals.2015.02.015

Moura, A., Kastenholz, E., \& Pereira, A. (2018). Accessible tourism and its benefits for coping with stress. Journal of Policy Research in Tourism, Leisure and Events, 10(3), 241-264. https://doi.org/10.1080/19407963.2017.1409750

MTSS. (2017). Carta Social_Relatório 2017. www.cartasocial.pt;

Neumayr, M., \& Meyer, M. (2010). In search of civicness: an empirical investigation of service delivery, public advocacy, and community building by civil society organizations. In T. Brandsen, P. Dekker, \& Evers, A. (Eds.), Civicness in the Governance and Delivery of Social Services (pp. 201-226). Nomos Verlagsgesellschaft mbH \& Co KG. https://doi.org/10.5771/9783845222400-201

Nogueira, R. (2017). Caracterização das Instituições do Terceiro Setor que compõem a União de Instituições Particulares de Solidariedade Social do Distrito de Bragança. Institituto Politécnico de Bragança. 
Noya, A., \& Clarence, E. (2008). Improving social inclusion at the local level through the social economy. Retrieved from: www.oecd.org/dataoecd/38/3/44688716.pdf?contentId=44688717. OECDLEED Programme

Nyaupane, G. P., \& Andereck, K. L. (2008). Understanding Travel Constraints: Application and Extension of a Leisure Constraints Model. Journal of Travel Research, 46(4), 433-439. https://doi.org/10.1177/0047287507308325

Nyman, E., Westin, K., \& Carson, D. (2018). Tourism destination choice sets for families with wheelchair-bound children. Tourism Recreation Research, 43(1), 26-38. https://doi.org/10.108o/02508281.2017.1362172

Pagán, R. (2015). The contribution of holiday trips to life satisfaction: the case of people with disabilities. Current Issues in Tourism, 18(6), 524-538. https://doi.org/10.1080/13683500.2013.860086

Papadimitriou, N., Plati, M., Markou, E., \& Catapoti, D. (2016). Identifying Accessibility Barriers in Heritage Museums: Conceptual Challenges in a Period of Change. Museum International, 68(3-4), 33-47. https://doi.org/10.1111/muse.12134

Patterson, I., Darcy, S., \& Mönninghoff, M. (2012). Attitudes and experiences of tourism operators in Northern Australia towards people with disabilities. World Leisure Journal, 54(3), 215-229. https://doi.org/10.108o/o4419057.2012.702452

Patterson, Ian, \& Balderas, A. (2020). Continuing and Emerging Trends of Senior Tourism: A Review of the Literature. Journal of Population Ageing, 13(3), 385-399.

Porto, N., Rucci, A. C., Darcy, S., Garbero, N., \& Almond, B. (2019). Critical elements in accessible tourism for destination competitiveness and comparison: Principal component analysis from Oceania and South America. Tourism Management, 75, 169-185. https://doi.org/10.1016/j.tourman.2019.04.012

Portugal, S., \& Alves, J. (2015). Doenças raras e cuidado: um olhar a partir das redes sociais. In R. Barbosa and Portugal, S. (Eds.), Um olhar social para o paciente Actas do I Congresso Iberoamericano de Doenças Raras (pp. 34-40). Centro de Estudos Sociais. https://estudogeral.sib.uc.pt/handle/10316/81017

Ray, N., \& Ryder, M. (2003). “Ebilities”' tourism: an exploratory discussion of the travel needs and motivations of the mobility-disabled. Tourism Management, 24(1), 57-72. https://doi.org/10.1016/So261-5177(02)ooo37-7

Reynolds, F. (2002). An exploratory survey of opportunities and barriers to creative leisure activity for people with learning disabilities. British Journal of Learning Disabilities, 30(2), $63-67$. https://doi.org/10.1046/j.1468-3156.2002.00151.x

Richards, V., Pritchard, A., \& Morgan, N. (2010). (Re) Envisioning tourism and visual impairment. Annals of Tourism Research, 37(4), 1097-1116. https://doi.org/10.1016/j.annals.2010.04.011

Russell, D. (2009). Living arrangements, social integration, and loneliness in later life: The case of physical disability. Journal of Health and Social Behavior, 50(4), 460-475. https://doi.org/10.1177/002214650905000406

RUTIS. (n.d.). RUTIS - Rede de Universidades Seniores. Retrieved December 15, 2020, from http://www.rutis.pt/paginas/8/universidades-seniores/

Salamon, L. M., \& Anheier, H. K. (1992). In search of the non-profit sector. The question of definitions. Voluntas, 3(2), 125-151. https://doi.org/10.1007/BFo1397770

Salamon, L. M., Hems, L. C., \& Chinnock, K. (200o). The Nonprofit Sector:For What and for Whom?. The Johns Hopkins Comparative Nonprofit Sector Project.

Sedgley, D., Pritchard, A., Morgan, N., \& Hanna, P. (2017). Tourism and autism: journeys of mixed emotions. Annals of Tourism Research, 66, 14-25. https://doi.org/10.1016/j.annals.2017.05.009 
Shaw, G., \& Coles, T. (2004). Disability, holiday making and the tourism industry in the UK: a preliminary survey. Tourism Management, 25(3), 397-403. https://doi.org/10.1016/So2615177(03)00139-0

Small, J. (2015). Interconnecting mobilities on tour: tourists with vision impairment partnered with sighted tourists. Tourism Geographies, 17(1), 76-90. https://doi.org/10.108o/14616688.2014.938690

Smith, R. W. (1987). Leisure of disable tourists. Barriers to participation. Annals of Tourism Research, 14(3), 376-389. https://doi.org/10.1016/o160-7383(87)90109-5

Solish, A., Minnes, P., \& Kupferschmidt, A. (2003). Integration of children with developmental disabilities in social activities. Journal on Developmental Disabilities, 10(1), 115-121.

Thomas, C. (2007). Sociologies of Disability and Illness. Contested Ideas in Disability Studies and Medical Sociology. Palgrave Macmillan

Triantafillou, J., Naiditch, M., Repkova, K., Stiehr, K., Carretero, S., Emilsson, T., Di, P., Rastislav Bednarik, S. |, Brichtova, L., Ceruzzi, F., Cordero, L., Mastroyiannakis, T., Ferrando, M., Mingot, K., Ritter, J., \& Vlantoni, D. (2011). Informal care in the long--term care system Executive Summary.

Turner, R., Miller, G., \& Gilbert, D. (2001). The role of UK charities and the tourism industry. Tourism Management, 22(5), 463-472. https://doi.org/10.1016/So261-5177(01)0oo15-2

Tutuncu, O., \& Lieberman, L. (2016). Accessibility of hotels for people with visual impairments: From research to practice. Journal of Visual Impairment and Blindness, 110(3), 163-175.

UN-United Nations. (2007). A/RES/61/106: Convention on the rights of persons with disabilities.

Vasileiou, K., Barnett, J., Thorpe, S., \& Young, T. (2018). Characterising and justifying sample size sufficiency in interview-based studies: Systematic analysis of qualitative health research over a 15year period. BMC Medical Research Methodology, 18(1), 148.

Venema, E., Vlaskamp, C., \& Otten, S. (2018). The role of volunteers in the social integration of people with intellectual disabilities. Research and Practice in Intellectual and Developmental Disabilities, 5(2), 154-167. https://doi.org/10.108o/23297018.2018.1443022

Verdonschot, M. M. L., de Witte, L. P., Reichrath, E., Buntinx, W. H. E., \& Curfs, L. M. G. (20oga). Community participation of people with an intellectual disability: A review of empirical findings. Journal of Intellectual Disability Research, 53(4), 303-318.

Verdonschot, M. M. L., de Witte, L. P., Reichrath, E., Buntinx, W. H. E., \& Curfs, L. M. G. (20ogb). Impact of environmental factors on community participation of persons with an intellectual disability: A systematic review. Journal of Intellectual Disability Research, 53(1), 54-64.

Vieira, T. (2015). Os papéis das organizações do terceiro setor na resposta aos problemas sociais. University of Coimbra.

White, D. D. (2008). A Structural Model of Leisure Constraints Negotiation in Outdoor Recreation. Leisure Sciences, 30(4), 342-359. https://doi.org/10.1080/01490400802165131

Whitehead, D., \& Whitehead, L. (2016). Sampling data and data collection in qualitative research. In Z. Schneider \& D. Whitehead (Eds.), Nursing and Midwifery Research (pp. 111-126). Elsevier. http://dx.doi.org/10.1016/B978-0-7295-4230-2.00007-9

Yau, M., McKercher, B., \& Packer, T. (2004). Traveling with a disability. Annals of Tourism Research, 31(4), 946-96o. https://doi.org/10.1016/j.annals.2004.03.007

Zajadacz, A. (2014). Sources of tourist information used by deaf people. Case study: the polish deaf community. Current Issues in Tourism, 17(5), 434-454. https://doi.org/10.1080/13683500.2012.725713

Zhang, L., \& Zhang, J. (2018). Impacts of leisure and tourism on the elderly's quality of life in intimacy: A comparative study in Japan. Sustainability (Switzerland), 10(12). https://doi.org/10.3390/su10124861

Received: $16 / 12 / 2020$

Accepted: 21/03/2021

Coordinating editor: Giacomo Del Chiappa 